\title{
Research on the Inspiration and Reference of Foreign Motivation Theory to Language Teaching Reform in China
}

\author{
Linling Tong \\ Jingdezhen Ceramic Institute, Jingdezhen, Jiangxi 333403, China
}

\begin{abstract}
Keywords: Foreign language learning motivation theory; Inspiration; Maintain
\end{abstract}
\begin{abstract}
The study of foreign language learning motivation begins with Gardner and Lambert, is the research under the framework of social psychology. Since the 1990s, there have been several new theories of motivation research, such as expectation-value theory and attribution theory. The development of motivation theory for Chinese foreign language teaching is mainly reflected on how to stimulate and maintain students' foreign language learning motivation in foreign language teaching classroom. This paper attempts to discuss the way and method of foreign language teaching reform in our country by combining the relevant principles of motivation theory and its development.

In the field of education, more and more attention are paid to how to teach students to learn today, such as learning motivation, learning interest and other non-intellectual factors on the impact of student learning, which increasingly arousing widespread concern by the education department, in college English teaching reform, we have encountered a variety of problems in the daily teaching. In order to avoid too much failure, some students don't want to take the initiative to try in the study; although the IQ of some students is not bad, but in the learning initiative and enthusiasm aspects, there is not existing a big enough; other students can not focus on the knowledge being learned due to excessive anxiety, so that the decline appears in academic performance and so on. All of these problems can be attributed to learning motivation. This paper attempts to discuss the motivation theory and its development situation to explore the way and method of teaching reform on our university English teaching.
\end{abstract}

\section{Motivation and Learning Motivation}

Motivation is to stimulate and maintain the individual to carry out activities, and lead to the activities of a mental orientation towards a goal or motivation. Learning motivation refers to an internal motivation to directly promote students' learning, which is a requirement to inspire and guide students to learn. It is an important non-cognitive factor that affects students' learning. Cognitive psychologists divide learning motivation into external learning motivation and internal motivation. External learning motivation refers to the fact that people are motivated by external incentives which are not in the activity, and out of the activity, they are interested in the results of the study. On the contrary, for the internal learning motivation, motivation satisfaction is within the activities, not outside the activities, it does not require external incentives, punishment to make the action point to achieve the target, because the action itself is a driving force. External motivation emphasizes external stimuli, such as incentives, good grades, praise, etc.; intrinsic motivation emphasizes learning behavior itself bringing satisfaction, pleasure and so on. Many studies have shown that, in the long run, intrinsic motivation is more conducive to foreign language learning.

\section{The Motivation Theory}

Since the eighties of the last century, the following motivational theories have had a profound impact: the expectation-value theory argues that the motivation of an individual's accomplishment is determined by his expectations of the likelihood of success of the task and the value given to it. Individuals believe that the greater the likelihood of achieving the goal, the greater the incentive value obtained from this goal, the greater the motivation for the individual to complete the task. Attribution theory points out that the outcome of the behavior is attributable to three factors: control, 
personal responsibility and stability. Control refers to whether the individual is introverted or outwardly. Introverted people tend to attribute success or failure to personal ability, effort, etc., while the people with dumping tend to attribute it to external factors; personal responsibility refers to the individual in the factors they need to bear the responsibility, and due to factors that individuals can control, you need a high sense of responsibility. The stability and instability of attribution determines whether individuals will strive to do better.

Objective theory holds that motivation is the result of cognitive treatment of task objectives. There are two main objectives: phenotypic goals and mastery goals. Phenotypic goals refer to learners in order to obtain a good ability to evaluate, to avoid bad ability to evaluate the effort; mastery goals refer to the learner in order to master the knowledge to improve the ability to work. Therefore, learners with a basic tendency to master a goal are more willing to accept challenges and persevere than learners who tend to be phenotypic goals.

The theory of self-determination is the development of the traditional external / inner theory, that is, according to the theory of self-determination, external motivation and intrinsic motivation are no longer two aspects of opposition. On the contrary, the intrinsic motivations of self-determination and the external motivation control are seen as continuum of four types of motivations: external adjustment motivations, projection adjustment motives, identity adjustment motivations, and fusion motivations.

Williams and Burden were based on cognitive and social constructivist motivational frameworks to define motivation as a "cognitive and emotional awakening that leads to conscious decisions to take action and lead to sustained mental and / or physical effort for a period of, the purpose is to reach a (or one group) established goals "[1]. Motivation is enhanced with the level of awakening up to the best degree; further enhancement of wake-up will lead to diminishing motivation. Low degree of awakening, students prone to boredom; while waking up too high, the performance of students is anxious. The other two factors that affect the motive are making decisions and paying sustained mental and / or physical strength. Individuals may want to do something for some reason, but whether to do it or do it and persist, mainly restricted by three aspects: (1) the factors that are related to the target of the motivation, ie the desired value; (2 ) And individual-related factors, namely, the individual's motivation, motivation type, causality and control concept; (3) environmental conditions factors.

Shumann and his colleagues studied the second language acquisition from the perspective of neurobiology, and on this basis, he proposed a continuous learning model [2], which indicates that the brain evaluates the received stimulus and further causing the learner's emotional response, the process is called motivation. This stimulus evaluation involves five aspects: newity, attraction, goal / meaning, processing mechanism, and individual and social image. The strength and nature of language learning motivation is determined by the arrangement and combination of these stimulus evaluations.

\section{The Enlightenment of Motivation Theory on the Reform of Foreign Language Teaching in China}

The motivation theory of studying foreign language learning helps us to better understand the psychological, social factors and individual differences of foreign language learning. It aims to stimulate and maintain learners' motivation in foreign language learning. Dornyei argued that the motivational component of the language level and the learner level is relatively fixed and difficult to control, so it is important to start and maintain the learners' foreign language learning motivation from the perspective of learning scenarios [3]. Chinese foreign language teaching is far from the use environment of the target language, coupled with China's large population, small class teaching is difficult to carry out. In addition, education teachers in the traditional mode is the authority of thinking, forming a foreign language classroom, "the teacher speak, students listen, and take notes", which lead to the dumb English. In foreign language learning purposes, there have been scholars put forward" certificate motivation" argument [4]. Based on the above factors, I believe that to stimulate and maintain the students' motivation to learn should pay attention to several aspects: 
First, make the course relevant to the student to the maximum extent possibly. Under the premise existing syllabus, it is particularly important for teachers to increase the content of the students' interest in the teaching and the contents of the work and research related to the students in the future. Increasing the content of interest of students, in fact, from the perspective of internal motivation, to improve the classroom atmosphere, to stimulate students' curiosity, and thus more cooperate with teachers.

Second, enhance the goal awareness of the learners to learn foreign language. Teachers should help students to establish long-term goals of foreign language learning in order to stimulate the intrinsic motivation, and to maintain the long-term motivation, so that students participate in the formulation and implementation of the target, thereby enhancing the students' self-determination, in order to play the student's foreign language learning initiative and consciousness.

Third, help students to form a more practical learning concept. Whether the reality of the learning concept to a large extent determine the learners for the progress of the rate of speed expectations. Many domestic foreign language schools attract students, to obtain greater economic profits, at the "seven days to speak fluent English", "Hundred Days of proficiency in English" and other advertising language. Similar ad overwhelming results make it easy for learners to form a foreign language (English) is an extremely simple concept, and when learners realize that they have not made such great progress, a strong sense of frustration will hurt the existing learning motivation. Therefore, it is particularly important for students to understand that foreign language learning is necessary to invest a lot of time, energy to establish a correct learning concept.

Fourth, cultivate learners' self-confidence. The most direct way to encourage and praise students is that they can take the initiative to complete the learning task with confidence. Brophy has instructed teachers how to make effective recognition, for example, to indicate the details of progress, or to attribute success to efforts and suggest that similar success may be achieved in the future [5]. In this way, students will feel the success from their own efforts, thereby enhancing self-confidence, and willing to pay more effort to achieve greater success.

Fifth, cultivate students' ability to autonomously learn. The number of students, besides, the personality differences, so that foreign teachers want to take care of each student, to adapt to each student becomes impossible. In this case, it is more urgent for the learners to gradually discover the best and most suitable learning methods and techniques, as well as the cultivation of autonomous learning ability.

Sixth, encourage positive self-evaluation. Satisfaction and pleasure after the learners complete the task will determine how the teacher to take the following learning tasks. Through the use of appropriate strategies, teachers can help learners to actively evaluate themselves and encourage them to be proud of their progress.

\section{Conclusion}

Factors that affect the motivation of foreign language learning are complex and diverse, so we can't just follow any one model to think. Under the current environment of college English teaching reform, foreign language teachers can't think that as long as they can be loyal to language materials, they can control the classroom and create a learning environment conducive to learning. Teachers should try to understand the needs and hope of students, and then can better stimulate and maintain the motivation of students to learn. Teachers play a role in teaching, guiding, while the role of students is the main body of learning, and they really play a subjective initiative to obtain foreign language learning progress. The above are some suggestions and views of the motivation theory of college English teaching reformby author, hoping that the majority of English teachers pay more attention to students' English learning motivation, combining with classroom teaching to help students learn English, regard it as a funny thing.

\section{References}

[1] M. Willams, R.L. BURDEN. Psychology for Language Teachers [M]. Beijing: Foreign 
Language Teaching and Research Press, 2000.

[2] J.H. Shumann. The neurobiology of affecting language [M]. Oxford: Blackwell Publishers, 1998.

[3] Z. Drnyei. Motivation in second and foreign language learning [J]. Language Teaching, 1998(31).

[4] H.F. Hua. Discussion on English learning motivation and strategy research [J]. Foreign Language Community, 1998 (3).

[5] J. Brophy. Teacher praise: a function analysis [J]. Review of Educational Research, 1981(1). 